\title{
A África e eu
}

\author{
ALBERTO DA COSTA E SILVA
}

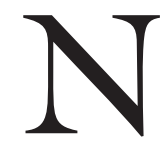

OS Últimos Dias de minha infância li, como tantos meninos de meu tempo, As minas do rei Salomão e os romances de Edgard Rice Burroughs, e acompanhei as fitas de cinema e as histórias em quadrinhos de seu herói, Tarzã, e também as de Jim das Selvas e de Tim e Tom na África Oriental.
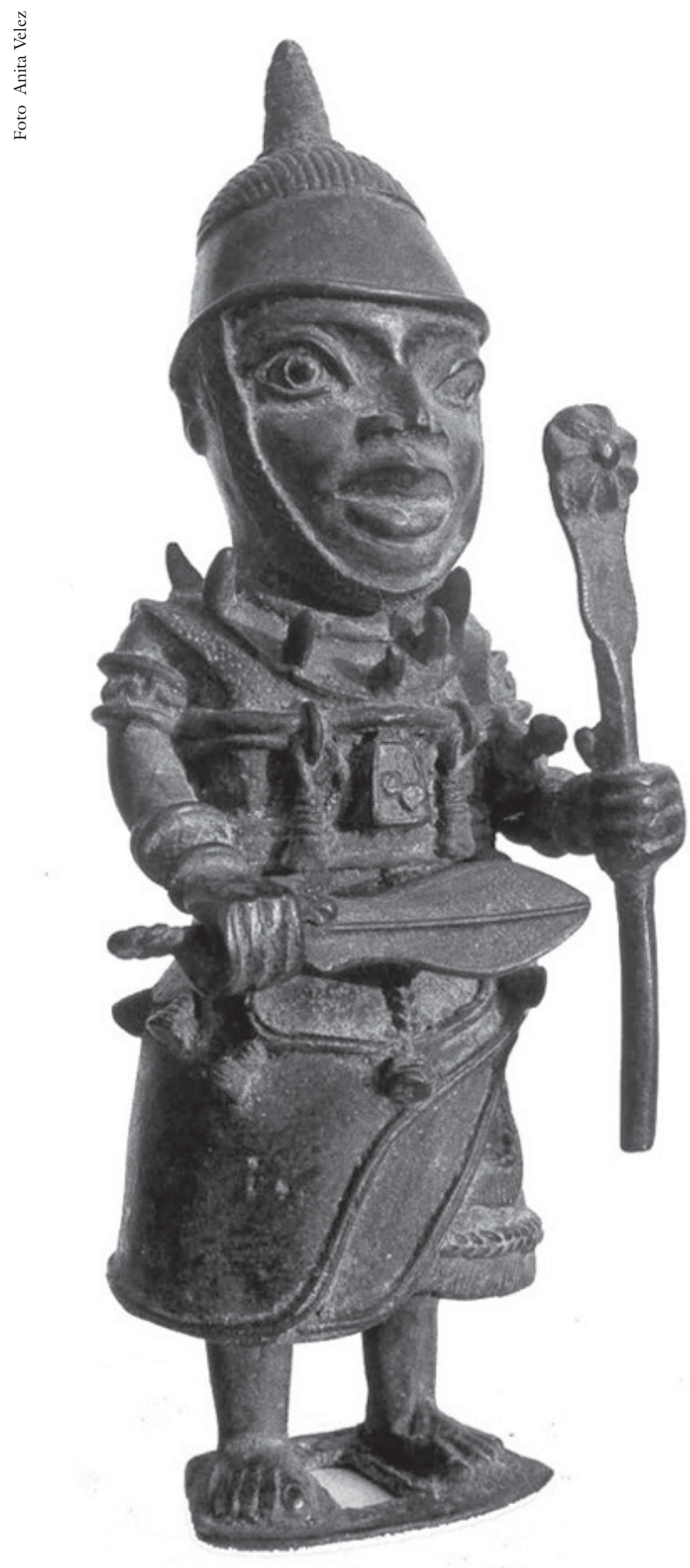

Confesso que ainda guardo no centro da alma essa África onde eram possíveis todas as fantasias da aventura. Mas a outra, aquela em que se viciaram a minha curiosidade e imaginação, eu a descobriria, a caminho dos meus 16 anos, incompleta e fragmentada pela distância e pelo tempo, dentro de mim e ao meu lado, ao ler pela primeira vez Casa grande e senzala. Terminado o livro, que me parecia sem ponto final, voltei ao seu começo e o reli inteiro, num deslumbramento sem bordas. Quando contei a um professor, Herbert Parentes Fortes, o meu entusiasmo e como havia corrido para Sobrados e mocam$b o s$, esse piauiense formado na Bahia me recomendou Nina Rodrigues e Manuel Querino. Foi com esses três autores, e com Arthur Ramos, que, adolescente, me convenci de que a escravidão fora o processo mais importante de nossa história e que, como o escravo não nascia no navio negreiro, se impunha conhecer a África, se queríamos entender o Brasil. De Os africanos no Brasil, eu repetia para mim mesmo alguns parágrafos que me contavam, ademais, que as

\section{Bronze de Benin}


relações entre o nosso país e o continente africano não se haviam restringido ao tráfico negreiro e que, em conseqüência dele, tinham sido muito mais ricas. Lá estavam a vinculação entre uma guerra santa islâmica no centro da África e a rebelião dos malês, em 1835, na Bahia, e a história de um traficante de escravos brasileiro, Francisco Félix de Souza, que se tornou um potentado africano, e as viagens comerciais de um certo Lourenço Cardoso entre Lagos e Salvador. Esses enredos continuam comigo até hoje - e com eles não é raro que sonhe.

Desde aquele dia, em 1947, em que abri com a espátula Casa grande \& senzala, não tirei a atenção de tudo o que via sobre a África. E era quase nada: algumas notícias de jornal, uma e outra reportagem fotográfica em revista norteamericana sobre, por exemplo, arte baulê ou senufo, os amuralhados do Grande Zimbábue ou os pigmeus do Congo, um volume desemparceirado da obra de Hermenegildo Capello e Roberto Ivens, De Angola à Contracosta, adquirido, do mesmo modo que Civilizations negro-africaines, de Maurice Delafosse, num sebo da Rua São José, no Rio de Janeiro, e os Diários de Viagem de Lacerda e Almeida, publicados graças a Augusto Meyer e Sérgio Buarque de Holanda. No Brasil, o silêncio sobre a África era quase absoluto, como se não tivéssemos nada a ver com ela. Quando muito, a palavra aparecia em textos a respeito da influência da escultura africana sobre a arte moderna.

Eu estava, desde os meus 19 anos, a curar-me em Campos do Jordão, desiludido, pela doença, de vir a ser antropólogo e entregue à minha outra paixão, a poesia, quando li, creio que em 1951, a série de artigos que Gilberto Freyre escreveu, na revista O Cruzeiro, para as fotografias de Pierre Verger, sobre as comunidades de brasileiros no golfo do Benin. Vi-me, então, com saudades de Nina Rodrigues, que fora o primeiro a dar notícia de que, se no Brasil continuava a África, nesta ficara um pedaço do Brasil.

Quando Gana se tornou independente, em 1957, eu cursava o último ano do Instituto Rio Branco, às vésperas de virar diplomata. Os jornais chegavam cheios de matérias sobre a África, mas, se esbanjavam fotos de Nkrumah, só raramente nos mostravam o asantehene ou rei dos axantes, e era destes, e dos fantes, e dos gás, e dos adagmés, e dos gonjas, e dos dagombas, e dos maprúsis que eu, em vão, esperava notícias.

Meses depois, vi-me a cuidar, no Ministério das Relações Exteriores, do comércio com a Ásia e a África. Ainda que o Japão tomasse mais da metade do meu tempo e estivesse sempre a exigir urgência, sobravam algumas horas por semana para ler os relatórios e as publicações que vinham das embaixadas em Londres, Paris, Washington, Lisboa e Bruxelas sobre um continente que se tornava independente. Nesses textos era raro que a atenção se projetasse para um passado de mais de 50 ou 60 anos, para além da época em que a maior parte da África fora submetida ao controle europeu. Mas havia remédio para a minha curiosidade: na biblioteca do Itamaraty encontrei, entre outros livros, o Esmeraldo 
de Situ Orbis, de Duarte Pacheco Pereira, e O “manuscrito" Valentim Fernandes, e ali pude ler, em Ramúsio, a Descrição da África, de Leão Africano, as Navegações, de Cadamosto e Pedro de Sintra, e a narrativa da viagem do piloto anônimo à Ilha de São Tomé.

Em 1960, servia como terceiro secretário na Embaixada do Brasil em Lisboa, e meu chefe, Francisco Negrão de Lima, sabedor de meu interesse pelo continente africano, confiou-me, ademais de outros temas, o acompanhamento do que se passava na África portuguesa. Aprendi a ler os jornais locais de cabeça para baixo e com o sinal invertido e passei muitas horas a conversar com estudantes angolanos, cabo-verdianos, são-tomenses e moçambicanos sobre suas aflições e esperanças. E sobre a história tradicional de suas gentes.

Certa manhã, fui chamado à sala do embaixador Negrão de Lima, e este me anunciou que iria acompanhá-lo, em fins de setembro, às cerimônias da independência da Nigéria. E lá fomos, para surpresas para as quais minhas leituras não me tinham preparado. Ainda na escada, ao descer do avião, vimos oficiais e soldados, de uniforme cáqui, com um debrum vermelho no colarinho, calças curtas e meias longas, como se fossem ingleses, e três ou quatro rapazes de terno escuro à européia, que pareciam ter sido colados um minuto antes sobre uma tapeçaria medieval ou sobre os afrescos de Benozzo Gozzoli na Capela Médici, em Florença, tal era a riqueza de formas e de colorido das roupas de todos os demais que nos esperavam. Diante da tristeza de nossos fatos e da economia dos vestidos escorridos de nossas mulheres, a abundância de panos - sedas, algodões, damascos, veludos - com que se trajavam de alegria nigerianos e nigerianas, e os bordados que lhes enfeitavam os decotes, e os turbantes, casquetes, gorros e chapéus emplumados que lhes cobriam as cabeças, não permitiam dúvida sobre a derrota européia em matéria de roupagem.

No caminho do aeroporto para o hotel, não me foi difícil perceber que em Lagos o traçado europeu das ruas centrais corria por sobre uma cidade africana e que esta se impunha sobre a outra, sempre que a deixavam. Os dias seguintes acentuaram a impressão da chegada: um século de domínio britânico não havia resultado numa mescla como a que se dá com o café, o açúcar e o leite, mas, sim, no tipo de mistura que se processa quando pomos numa vasilha grãos crus de feijão e de milho e a sacudimos uma ou duas vezes.

A grande emoção esperou pela véspera da partida. Os dois rapazes nigerianos que estavam à nossa disposição nos levaram ao Brazilian Quarter, o antigo bairro dos brasileiros, agudás ou amarôs, com seus sobrados e casas térreas que seriam idênticas às das velhas ruas de Salvador ou do Rio de Janeiro, se estivessem cobertas de telhas em vez de folhas-de-flandres. Depois, fomos até o cemitério de Ikoyi, comover-nos diante dos túmulos dos brasileiros e de seus descendentes. Enquanto lia as lápides, sentia que tinha mais razões do que Frobenius para repetir baixinho: - Unser Afrika, a nossa África, a minha África. 
Dois meses após o regresso da Nigéria, mandaram-me por duas semanas a Adis-Abeba. No caminho, fiquei cinco dias no Cairo e passei por Cartum. Logo depois, fui a Gana, de onde me desloquei de automóvel pelo Togo e o então Daomé até a Nigéria. E, algumas semanas mais tarde, viajei ao Senegal, à Costa do Marfim e aos Camarões e, novamente a Gana, Togo, Daomé e Nigéria. De volta a Lisboa, já no dia seguinte segui para Angola, cujas principais cidades percorri.

A essas viagens à África seguiram-se muitas outras, espaçadas ao longo de 30 anos. Revisitei mais de uma vez aqueles países, conheci outros, como a Serra Leoa, a Libéria, o Gabão, o então Zaire e o Quênia; e, quando embaixador na Nigéria e na República do Benim (ex-Daomé), vivi, de 1979 a 1983, em Lagos, onde me senti em casa, como mais um agudá.

Aquelas primeiras viagens coincidiram com o grande impulso que tomaram, sobretudo na França, na Grã-Bretanha e nos Estados Unidos, os estudos de história africana, uma história que fora até então desprezada ou negada. De 1960 data o primeiro número de The Journal of African History, do qual devo ter sido um dos mais antigos assinantes brasileiros, e que tinha a peculiaridade de dedicar-se exclusivamente à História, enquanto, por exemplo, a revista Africa (do International African Institute) e o Bulletin de l'Institut Français de l'Afrique Noire dividiam suas páginas com outras disciplinas.

Chegado a uma cidade africana, procurava tempo para um salto às livrarias, mas onde me abastecia das novidades era mesmo em Lisboa. Se dei com The western slave coast and its rulers, de C. W. Newbury, numa montra do Chiado, desencavei de uma tabuleiro de saldos A history of islam in West África, de J. Spencer Trimingham. Nos alfarrabistas não faltavam preciosidades. Neles adquiri as traduções inglesas de Und Afrika sprach, de Frobenius, e das viagens de Heinrich Barth. E os livros que não encontrava à venda, lia, muitas vezes, de empréstimo, como sucedeu com o Tableau geógraphique de l'Ouest africain an Moyen Age, de Raymond Mauny.

Cometi, na época, grandes pecados de intolerância intelectual. Como tinha ojeriza a Salazar e impaciência com o discurso oficial sobre a ação civilizadora de Portugal na África, punha de lado, por suspeita de propaganda, as publicações que recebia do Centro de Estudos Históricos Ultramarinos e de outras entidades do Estado português. Nas livrarias, passava ao largo das estantes onde ficavam os livros editados, anos antes, pela Agência Geral das Colônias (depois, do Ultramar) e pelo Centro de Estudos da Guiné Portuguesa. Hoje sei que a maioria deles é de boa e até de alta qualidade e lastimo não os ter então comprado. E cada vez que regresso a Lisboa, saio a catá-los de sebo em sebo. Neste e naquele livro, encontro, em sussurro ou em voz alta, a arrogância colonial, mas a perdôo pelas informações cuidadosamente recolhidas e pelo confronto com a minha própria arrogância - a arrogância de quem negava seriedade ou sinceridade a quem pensava diferente. 
A África e Eu

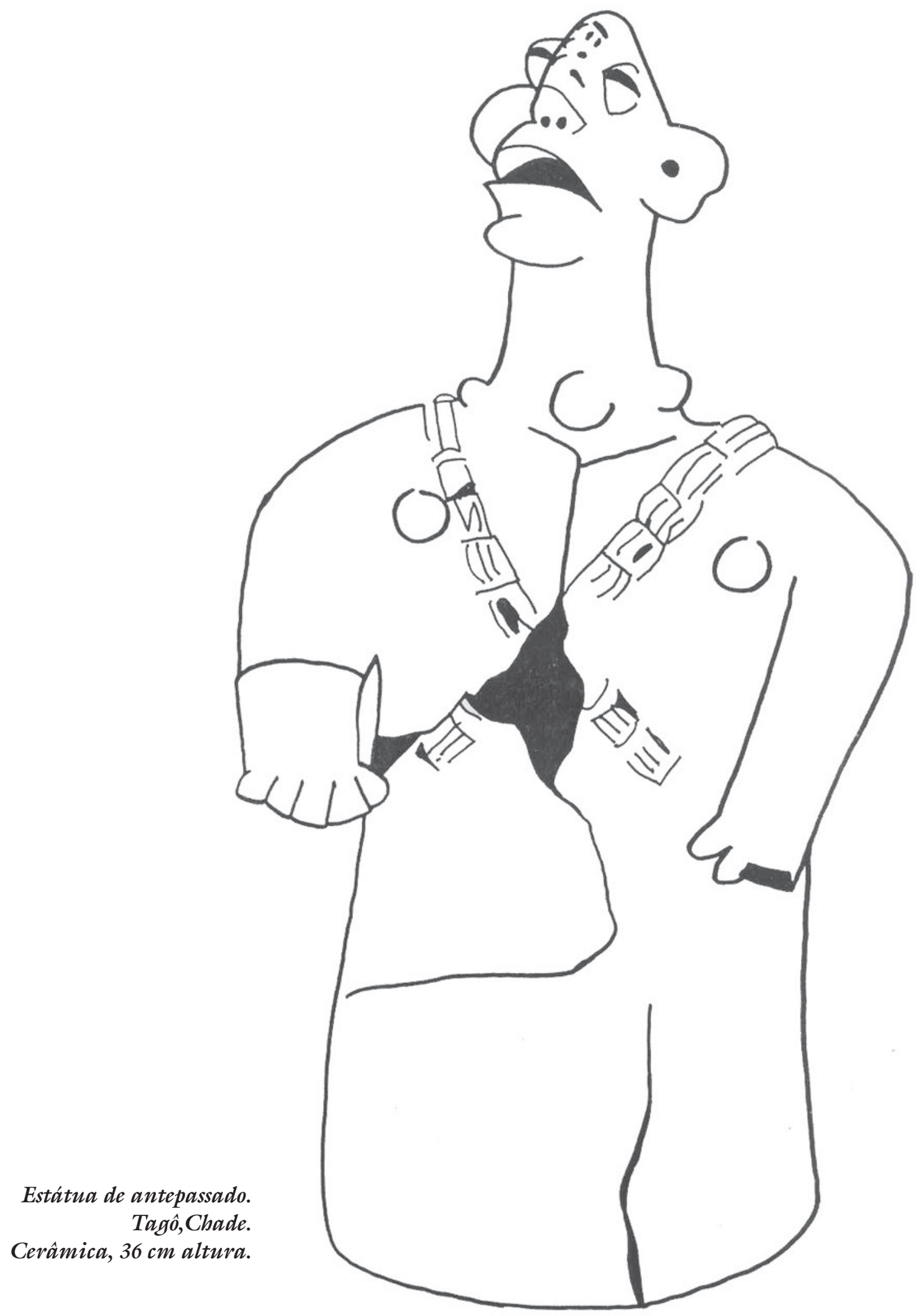


Não se abateu, ao longo dos anos, o meu interesse pela África. Por algum tempo, porém, não tive para as minhas leituras africanas senão alguns sábados e domingos, absorvido que sempre estive por um ofício que de mim exigia o estudo demorado e zeloso do país onde estava. Se em Washington era comum encontrar nas livrarias as obras que se iam publicando sobre a África, essas não apareciam em Caracas, Madri ou Roma. Nem sequer em Lagos. Mas, já então sabendo dos novos títulos pelas revistas que assinava, eu os encomendava a colegas diplomatas que serviam em Nova York, Londres ou Paris. Um deles, prestimosíssimo, foi José Guilherme Merquior. Este não só não tardava em cumprir os encargos, mas com freqüência dava uma olhada no livro pedido e, quando o lia, punha entre as páginas do volume uma carta ou um bilhete com suas impressões, a transbordarem de inteligência e sensibilidade. No exemplar que me mandou da obra hoje clássica de Jack Goody, Technology, tradition and the State in Africa, ele escreveu no próprio ante-rosto do voluminho que o retivera no fim de semana, tão interessante o achara, e me dizia por quê.

As minhas leituras tornaram-se mais disciplinadas e rigorosas desde que em 1975, em Madri, após uma acesa discussão sobre a guerra civil em Angola, Carlos Lacerda me cobrou, como um dever a que não poderia furtar-me, que começasse a escrever um livro sobre a África. Fiz os primeiros esboços de $A$ enxada e a lança ainda em Madri. E comecei a redigi-lo, algumas poucas pági-

Imagem de ancestral.

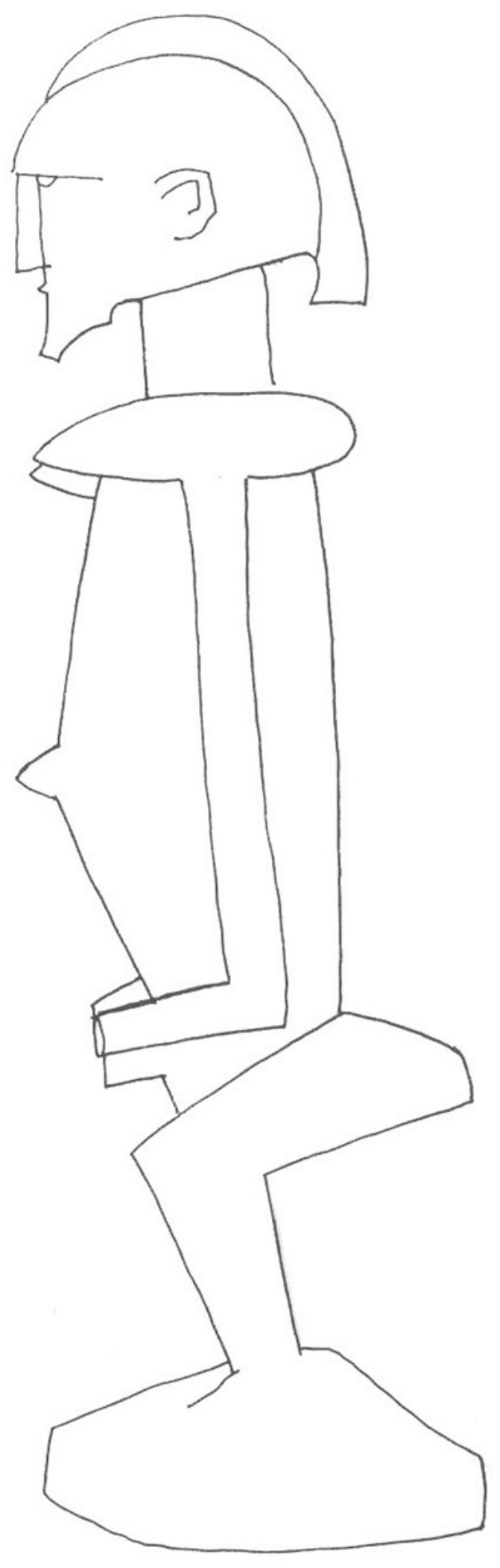
Dagon. $40,5 \mathrm{~cm}$ de altura. 
nas por semana, nos meus dois anos de Roma. Mas foi em Lagos que tomei impulso e passei a trabalhar nele diariamente, ainda que, às vezes, por não mais de meia hora. Dez anos mais tarde, no crepúsculo de minha missão como embaixador em Lisboa, logrei finalizar essa história das várias Áfricas antes da chegada dos portugueses.

O livro só foi impresso dois anos depois de terminado, e, mal saiu, senti a necessidade de corrigi-lo e atualizá-lo. Passei mais de um ano a preparar a segunda edição, publicada em 1996. Ao entregar os originais à Nova Fronteira, já arrumava, contudo, as velas para $A$ manilha e o libambo.

Ganhei seis anos de manhãs felizes e aventurosas escrevendo esse novo livro, sobre a história da África entre 1500 e 1700, com ênfase na escravidão. Se não o terminei antes foi porque, durante todo esse tempo, tive de dedicar muitíssimas horas a leituras que pouco ou nada tinham que ver com os textos que estava redigindo, mas me eram necessárias para não perder o rumo do que sobre a África e sua história constantemente se publica. Às vezes, ao receber novas revistas ou livros, vejo-me a reexaminar, para confirmá-las ou corrigi-las, idéias que pus em $A$ enxada e a lança ou em $A$ manilha e o libambo. Outras, alegro-me com a confirmação do que desentranhei de minhas leituras. Tenho agora sobre a mesa, por exemplo, dois livros que saíram, o primeiro, no ano passado, em Nova Delhi, e o segundo, há quatro ou cinco meses, em Nova York: The world of the Indian Ocean merchant, 1500-

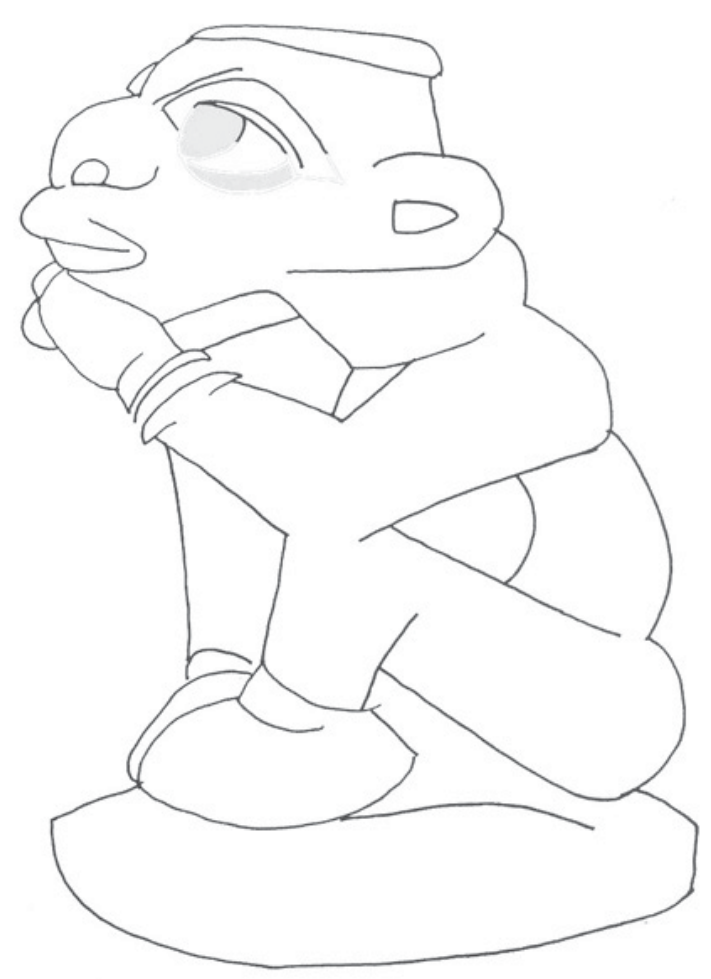
1800, de Ashin das Gupta, e The arabian seas: the Indian Ocean world of the seventeenth century, de R. J. Barendse. Ambos reforçam a minha convicção, a seguir a trilha de Vitorino Magalhães Godinho, de que, ao contrário do que tanto se tem escrito, os portugueses, holandeses e ingleses não conseguiram, nos séculos XVI e XVII, desarticular a rede comercial islâmica no Índico e assumir o controle das trocas no que era, desde muito, o mais mercantil dos oceanos. Dominaram, sem dúvida, a maior parte do intercâmbio marítimo entre a Europa e a Ásia, ou talvez - concedamos - quase todo 
ele, mas esse intercâmbio era pequenino, quando comparado com o volume e o ritmo das transações que se processavam entre o Japão, a China, o sudeste da Ásia, o que hoje é a Indonésia, a Índia, o Ceilão, o Golfo Pérsico, o Mar Vermelho e a costa oriental da África. Teria sido só no final do Setecentos que parte desse comércio começou a soltar-se das mãos, que o tinham bem apertado, dos povos do Índico, sobretudo dos árabes e dos indianos. Como isso se deu será contado em algum capítulo do novo livro que, em janeiro, começarei a escrever, sobre a África nos séculos XVIII e XIX e sua resistência ao avanço e domínio europeu. Voltarei, assim, aos romances, filmes e histórias em quadrinhos de minha meninice, mas com heróis ao contrário.

Alberto da Costa e Silva, diplomata e escritor, é presidente da Academia Brasileira de Letras (ABL). É autor, entre outras obras, de $A$ enxada e a lança: a África antes dos portugueses (1992) e A manilha e o libambo. A África e a escravidão de 1500 a 1700 (2002). 